\title{
A novel explanation of the psycho-religious mechanism behind suicide bombers and implications for dealing with terrorism
}

Quan-Hoang Vuong, Tam-Tri Le*, Hong-Kong T. Nguyen, Huyen Thanh T. Nguyen, Minh-Hoang Nguyen*

Centre for Interdisciplinary Social Research, Phenikaa University

Yen Nghia, Ha Dong, Hanoi 100803, Vietnam

*Correspondence: hoang.nguyenminh@phenikaa-uni.edu.vn; letamtri10@gmail.com

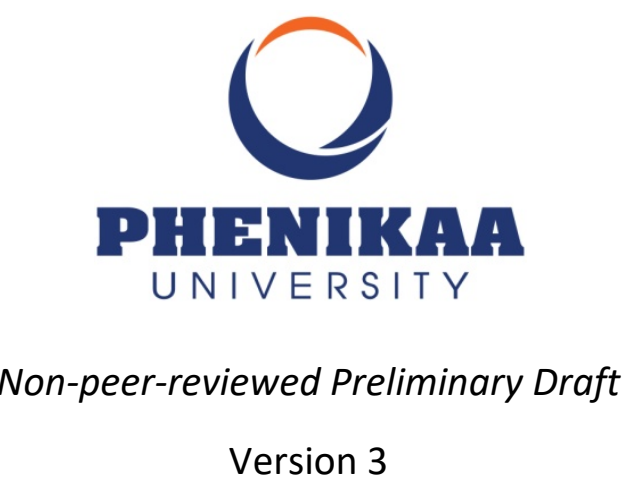

April 06, 2021

\begin{abstract}
The current study explores the psycho-religious mechanism behind the suicide bombers by examining deeper into the suicidal ideation process. Bayesian analysis was performed on a multinational dataset of 268 university students in Japan. The results suggest that: (i) within religious students, those with a higher sense of connectedness tend to have lower suicidal ideation compared to those with a lower sense of connectedness. ; and (ii) within students who are more likely to seek help from religious leaders, those with a higher sense of connectedness tend to have lower suicidal ideation compared to those with a lower sense of connectedness. These findings suggest a complex psycho-religious mechanism of suicidal ideation.

This manuscript is the first version of the study describing the logical framework and results of the study. Despite lacking many vital components, such as literature review, detailed explanation, and discussion of the results, we expect early reporting study's results to provide a valuable way
\end{abstract}


for understanding complex psycho-religious mechanisms behind the suicide bombers. More completed versions will be updated afterward.

\section{Introduction}

Between 1981 and 2011, approximately 2,297 suicide bombings took place in 36 countries, killing nearly 30,000 people (Hassan, 2014). The global trends indicate that, from the early 1990 s to the 2000s, suicide bombing did escalate sharply, so much that it was often said we were living in the "era of suicide bombings" (Pape, 2003; Shibley, 2002). However, data in recent decades suggest a gradual decline in suicide bombings worldwide: there were around 127 such attacks in 17 countries in 2020, a drop of $14.5 \%$ year-on-year (Schweitzer, Mendelboim, \& Hendler-Bloom, 2021). Even as there may be a downtrend, compared to other uses of force by terrorist groups and insurgents, suicide bombing remains the major method for generating a considerably larger number of casualties per attack (Horowitz, 2015). The fact of the matter is clear, suicide bombing-and suicide terrorism at large-poses a severe threat to humanity not only due to the magnitude of its material damage but also due to the immeasurable spread of terror and demoralization it brings.

However, attempts to study the psychological processes of suicide bombers face several big obstacles, such as safety (for researchers) and data confidentiality (related information is secured by governmental Intelligence agencies). It should not be noted that we use the term "suicide bombers" to represent all kinds of suicide terrorism (not only suicide bombing) because it is popular and easy to imagine. Scholars have debated the motives of suicide bombers but tend to agree that religiosity is a significant influencing factor (Horowitz, 2015). Additionally, extremist groups target youths for their recruitment operations, using different persuasion strategies (Darden, 2019). Therefore, understanding the underlying thought process in religious youths regarding suicide can be crucial in solving the multiplex problems of suicide terrorism.

Based on the rationale mentioned above, we examine the factors of religiosity, sense of connectedness, help-seeking behavior from religious leaders, along with their interactions toward suicidal ideation, using a sample of multinational university students. We use the Mindsponge theory (Q.-H. Vuong, 2016; Q. H. Vuong \& Napier, 2015) as the theoretical framework; and construct the models based on individuals' cost-benefit perception toward suicide - similar to the former study on suicide ideation mechanism (Nguyen et al., 2021). The current study aims to explore the psycho-religious mechanism in the human mind about the perception of suicide and how terrorist recruitment operations might exploit it. 


\section{Literature review}

\subsection{Religion and suicide research}

- No consensus

- Although there is protection against suicidal attempt, no effect against suicidal ideation (Gearing \& Alonzo, 2018; Lawrence, Brent, et al., 2016; Lawrence, Oquendo, et al., 2016)

\subsection{View of suicide in major religions}

\subsubsection{Christianity}

- It used to view suicide as sin, against God

- Now: pray for the dead, forgive suicide under the influence of depression, alcohol, drugs, etc.

(Catholic Church, 1994; Retterstøl \& Ekeberg, 2009)

\subsubsection{Buddhism}

- Open to interpretation, depend on moral value, emphasis on karma and reincarnation

(Promta \& Thomyangkoon, 2009)

\subsubsection{Islam}

- Forbidden explicitly; yet real number still high

- Strict law leads to even more hindrance to social connectedness

(Eskin et al., 2019; Okasha \& Okasha, 2009)

\subsubsection{Shinto}

- Mixed with Buddhism; return to nature, worship ancestors; sacrifice vs against nature (Kaneko et al., 2009)

\subsubsection{Confucianism and Taoism}

- Confucianism: worship ancestors, emphasize honor and legacy

- Taoism: worship ancestors (spirits), return to nature, immortality and Taoist heaven

(Fei, 2009; Hsu et al., 2009)

\subsubsection{Hinduism}

- Generally condemned, some practices condoned

- Individual's decision: dignified death; karma and reincarnation

(Vijayakumar, 2009)

\section{Main points}

- $\quad$ Not binary (life/death), but belief in other existence (life after death; death as transition) => Leads to: lower perceived cost of death; perception on leaving behind legacy (immortal) 


\section{Methodology}

\subsection{Logical framework}

We employed the Mindsponge mechanism for establishing the logical framework for the psychoreligious mechanism. Mindsponge is a theory explaining how an individual absorbs and rejects information based on a multi-filtering process. The process is driven by cost-benefit judgments that involve both rational and emotional aspects with trust evaluations. If the information is trustworthy, it is easier to influence the mindset; otherwise, the filters will prevent that information from entering deeper (Q.-H. Vuong, 2016; Q. H. Vuong \& Napier, 2015).

Before constructing the logical framework, it is essential to examine the concept of suicidal ideation in terms of information processing. Thus, we refer to the explanation of Nguyen et al. (2021) that those "who have suicidal thoughts in mind consider suicide an option when dealing with certain circumstances (e.g., depression, anxiety, perceived burdensomeness, loneliness, etc.)". When considering suicidal ideation as a constituent of an individual's cost-benefit judgment, one question emerges: "Does religious people have higher likelihood of suicidal ideation?". We expect the answer to be 'yes' through two assumptions:

1) Religious people tend to have higher accessibility to information regarding the value of death.

2) When people consider themselves religious, information is easier to be absorbed due to less rigorous trust evaluation process, and thus, suicidal option is perceived as less costly.

To test our assumptions, or in other words, to explore the psycho-religious mechanism of suicidal ideation, we conduct analyses following the logical framework shown in Figure 1:

Step 1: we initially examined the relationship between students' religiosity and suicidal ideation. The relationship can be explored using Model 1a below.

$$
\text { Suicide } \sim \alpha+\text { Religion }
$$

If there is no association or the association effect is not clear, we continue with Model $1 \mathrm{~b}$ below. As the sense of connectedness is a strong predictor of suicidal ideation through reducing the cost of help-seeking, it might help mediate the effect of religious feeling on suicidal ideation. Adding the interaction between being religious and sense of connectedness into Model $1 \mathrm{~b}$, we aim to see whether religous students with higher help-seeking cost (high sense of connectedness) are more likely to have suicidal ideation than religious students with low help-seeking cost (low sense of connectedness) and non-religious students.

$$
\text { Suicide } \sim \alpha+\text { Religion }+ \text { Religion } * \text { TCC }
$$

After completing Step 1, if the association between being religious and suicidal ideation exists (no matter it is conditional or not), it confirms our second assumption above that religious 
people have less rigorous trust evaluation towards death related information. Otherwise, the analysis will be stopped.

Step 2: Next, we need to examine our first assumption that religious people have higher accessibility to death-related information, but how? We suspect that the information can be assessable through the individual's religious leaders. A religious person might or might not have a religion, so it is vital to test whether religious people are more likely to seek help from religious leader when encountering emotional difficulties. Thus, we proposed Model 2a. If there is no association or the association effect is not clear, we continue with Model $2 b$ that considers the mediating role of sense of connectedness.

$$
\begin{aligned}
& \text { ReligionLeader } \sim \alpha+\text { Religion } \\
& \text { ReligionLeader } \sim \alpha+\text { Religion }+ \text { Religion } * \text { TCC }
\end{aligned}
$$

Step 3: If being religious is positively associated with the likelihood of seeking help from religious leaders, we continue to examine how the likelihood of seeking help from religious leaders associates with suicidal ideation through Model 3a. If there is no association or the association effect is not clear, we continue with Model $3 b$ that considers the mediating role of a sense of connectedness.

$$
\begin{aligned}
& \text { Suicide } \sim \alpha+\text { ReligionLeader } \\
& \text { Suicide } \sim \alpha+\text { ReligionLeader }+ \text { ReligionLeader } * \text { TCC }
\end{aligned}
$$

After completing Step 3, if the association between the likelihood to seek help from religious leader and suicidal ideation exists (no matter it is conditional or not), our first assumption that religious people are more accessible to information regarding the value of death can be supported. Specifically, that information is accessible through religious leaders who in any religion will tend explain the value of death according to their religion's doctrines. 


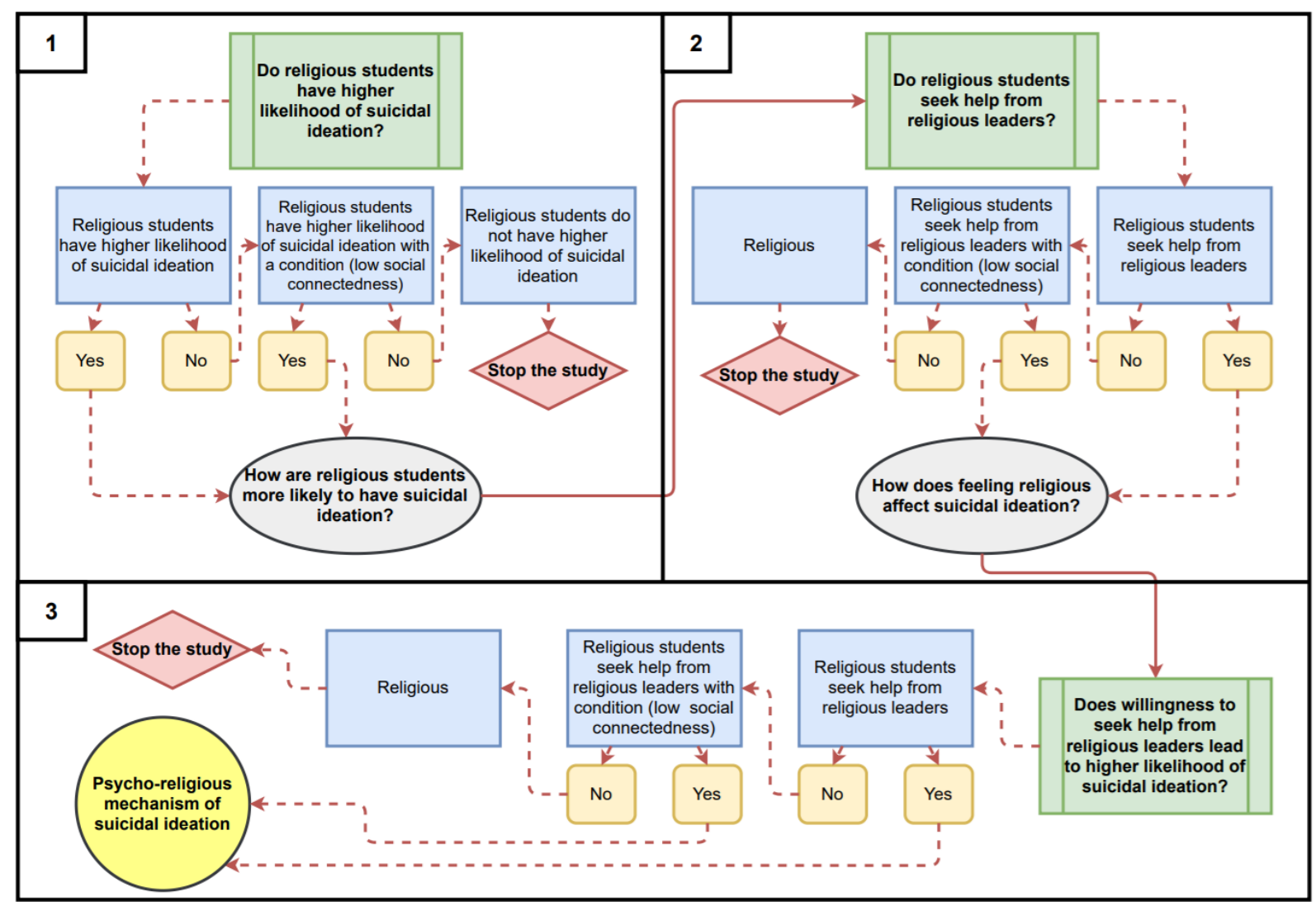

Figure 1: Logical framework of the psycho-religious mechanism

\subsection{Study sample}

We employed a multinational dataset of students' mental health and help-seeking behaviors. The dataset comprises responses from 268 students with different cultural and religious backgrounds.

\subsection{Statistical analysis}

We performed Bayesian analysis using the bayesvl R package (La \& Vuong, 2019; Q.-H. Vuong \& $\mathrm{La}, 2019)$ on the dataset. The simulations were set with 5,000 iteration, 2,000 warmup iterations, four Markov chains, and 'uninformative' priors. Variables utilized in the current study are described in Table 1.

\begin{tabular}{|c|c|c|c|}
\hline Name & Variable & Data type & Description \\
\hline Suicidal ideation & Suicide & Binary & $\begin{array}{r}\text { Suicidal ideation in the past two weeks } \\
\text { based on the PHQ-9 (Kroenke \& Spitzer, } \\
2002 ; \text { Kroenke, Spitzer, \& Williams, }\end{array}$ \\
\hline
\end{tabular}




\begin{tabular}{|c|c|c|c|}
\hline $\begin{array}{c}\text { Students' religious } \\
\text { feeling }\end{array}$ & Religion & Binary & $\begin{array}{c}\text { 2001). 'Yes' is coded as 1, 'No' is coded as } \\
0 .\end{array}$ \\
\hline $\begin{array}{c}\text { Help-seeking from } \\
\text { religious leaders }\end{array}$ & ReligionLeader & Continuous & $\begin{array}{c}\text { Whether thespondent considered } \\
\text { themselves as religious }\end{array}$ \\
\hline $\begin{array}{c}\text { Total } \\
\text { connectedness } \\
\text { and } \\
\text { companionship }\end{array}$ & TCC & Continuous & $\begin{array}{c}\text { The average score of likelihood to seek } \\
\text { help from religious leaders when } \\
\text { encountering emotional difficulties. The } \\
\text { data range from 1 to 7. }\end{array}$ \\
\hline $\begin{array}{c}\text { The total score of connectedness (4 } \\
\text { items) and companionship (1 item) } \\
\text { measured by the Social Connectedness } \\
\text { Scale developed by Lee and Robins (Lee } \\
\text { \& Robbins, 1995). The data range from } 6 \\
\text { to 48. }\end{array}$ \\
\hline
\end{tabular}

\section{Results}

\subsection{Model 1a}

Table 2: Model 1a's simulated posteriors.

\begin{tabular}{|c|c|c|c|c|}
\hline & Mean & SD & n_eff & Rhat \\
\hline Constant & -1.21 & 0.18 & 4607 & 1 \\
\hline Religion & -0.08 & 0.32 & 5122 & 1 \\
\hline
\end{tabular}

Model 1.a's posterior simulation suggests that religious affiliation has no clear association with suicidal ideation (see Table 2 and Figure 2). Thus, we continued performing Model 1.b. 


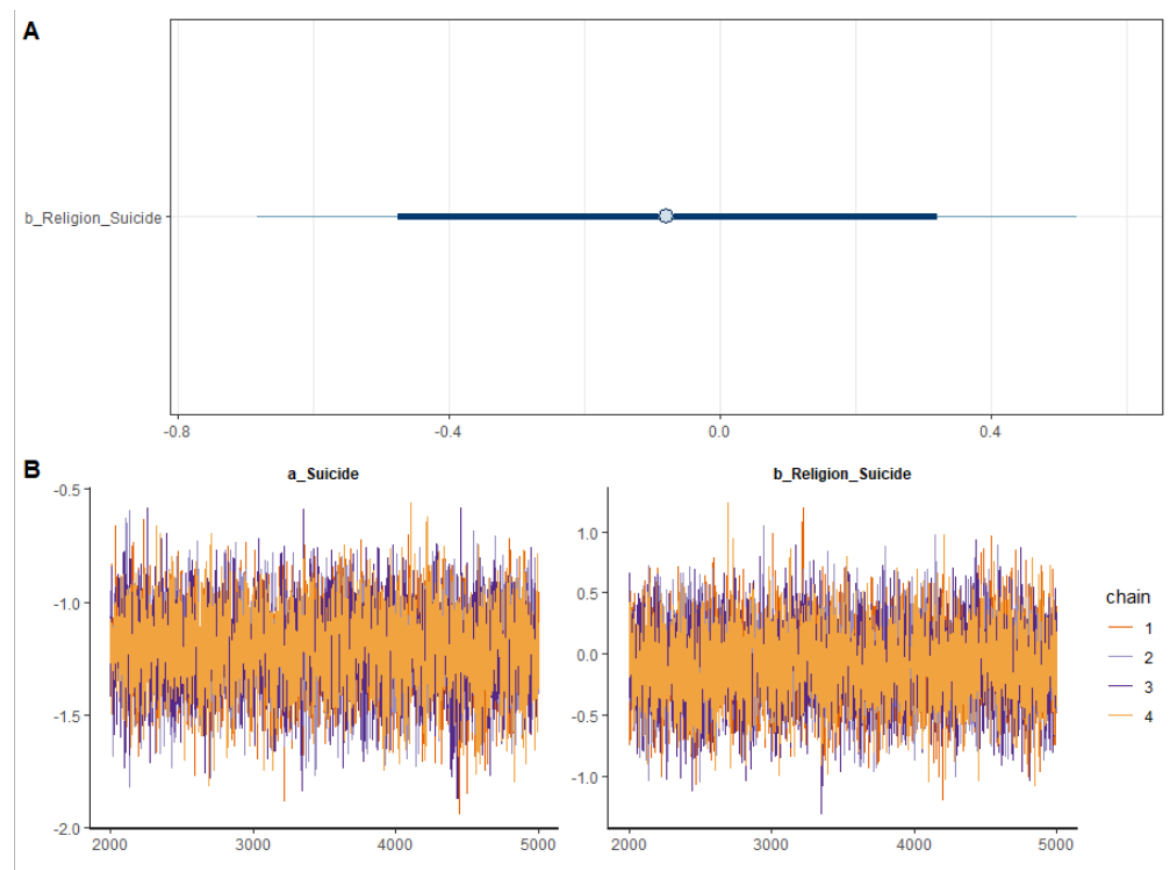

Figure 2: A - Interval plot for Model 1a. B - Trace plots for Model 1a
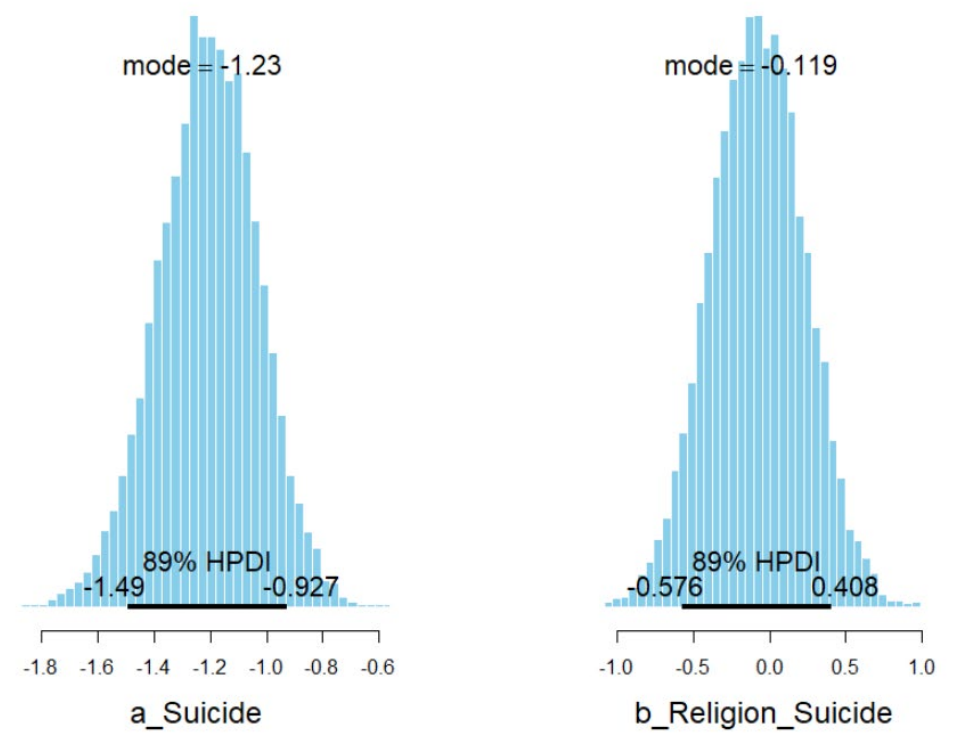

Figure 3: Distributions of Model 1a's posterior coefficients with HPDI at 89\%

\subsection{Model $1 b$}

Table 3: Model 1b's simulated posteriors. 


\begin{tabular}{|c|c|c|c|c|}
\hline & Mean & SD & n_eff & Rhat \\
\hline Constant & -1.21 & 0.18 & 5593 & 1 \\
\hline Religion & 5.14 & 1.30 & 3595 & 1 \\
\hline Religion*TCC & -1.15 & 0.29 & 3576 & 1 \\
\hline
\end{tabular}

Model $1 b$ 's diagnostic statistics indicate a good convergence of Markov chains ( $n \_$eff $>1,000$ and Rhat $=1$ ) and the model's high goodness-of-fit with the data (see Table 3 and Figures 4, 5-B). Within religious students, those with a higher sense of connectedness tend to have lower suicidal ideation than those with a lower sense of connectedness (see Figures 5-A). Figure 6 shows that the associations are highly reliable.

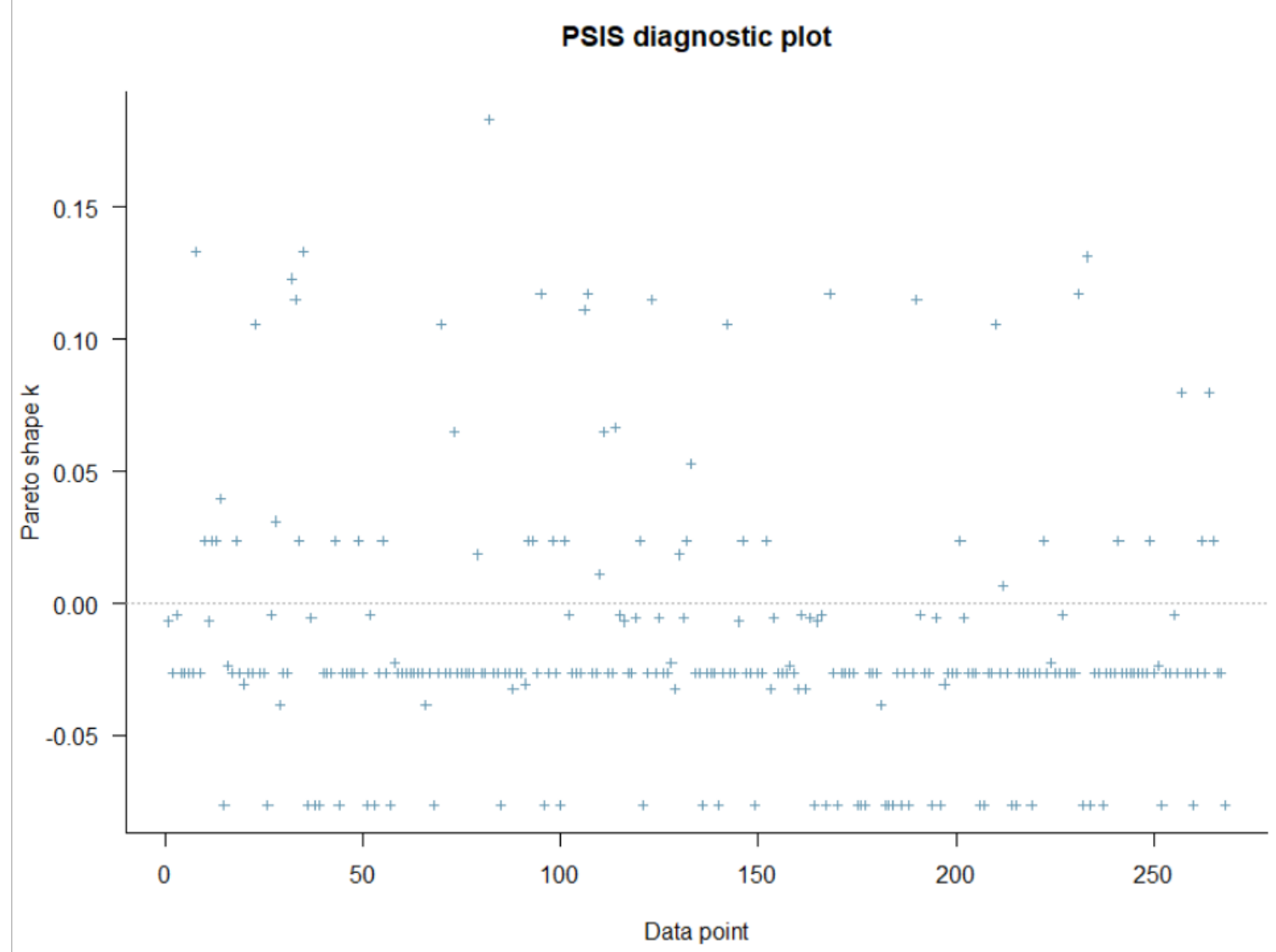

Figure 4: Model 1b's PSIS diagnostic plot. 


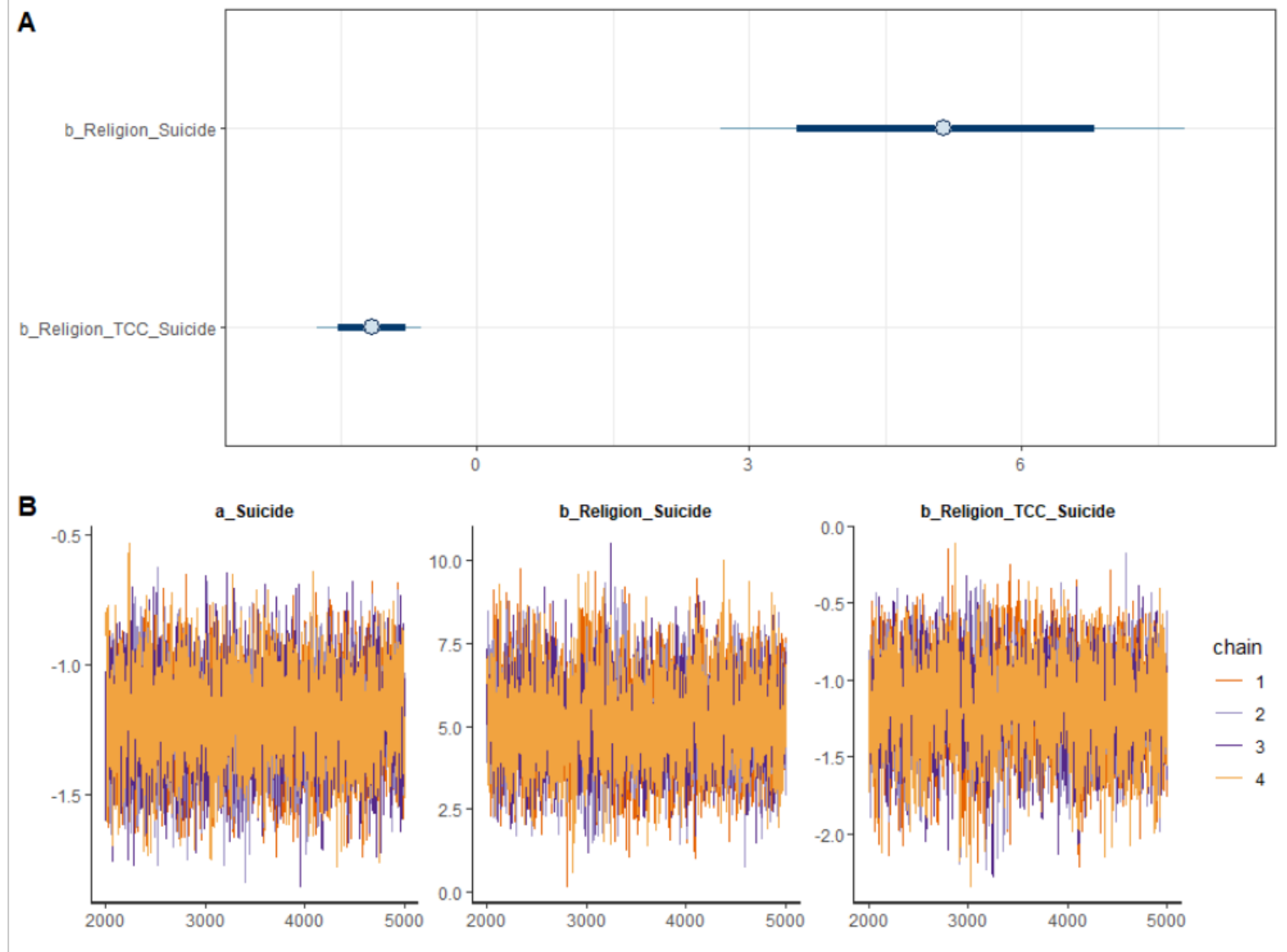

Figure 5: A - Interval plot for Model 1b. B - Trace plots for Model 1b 

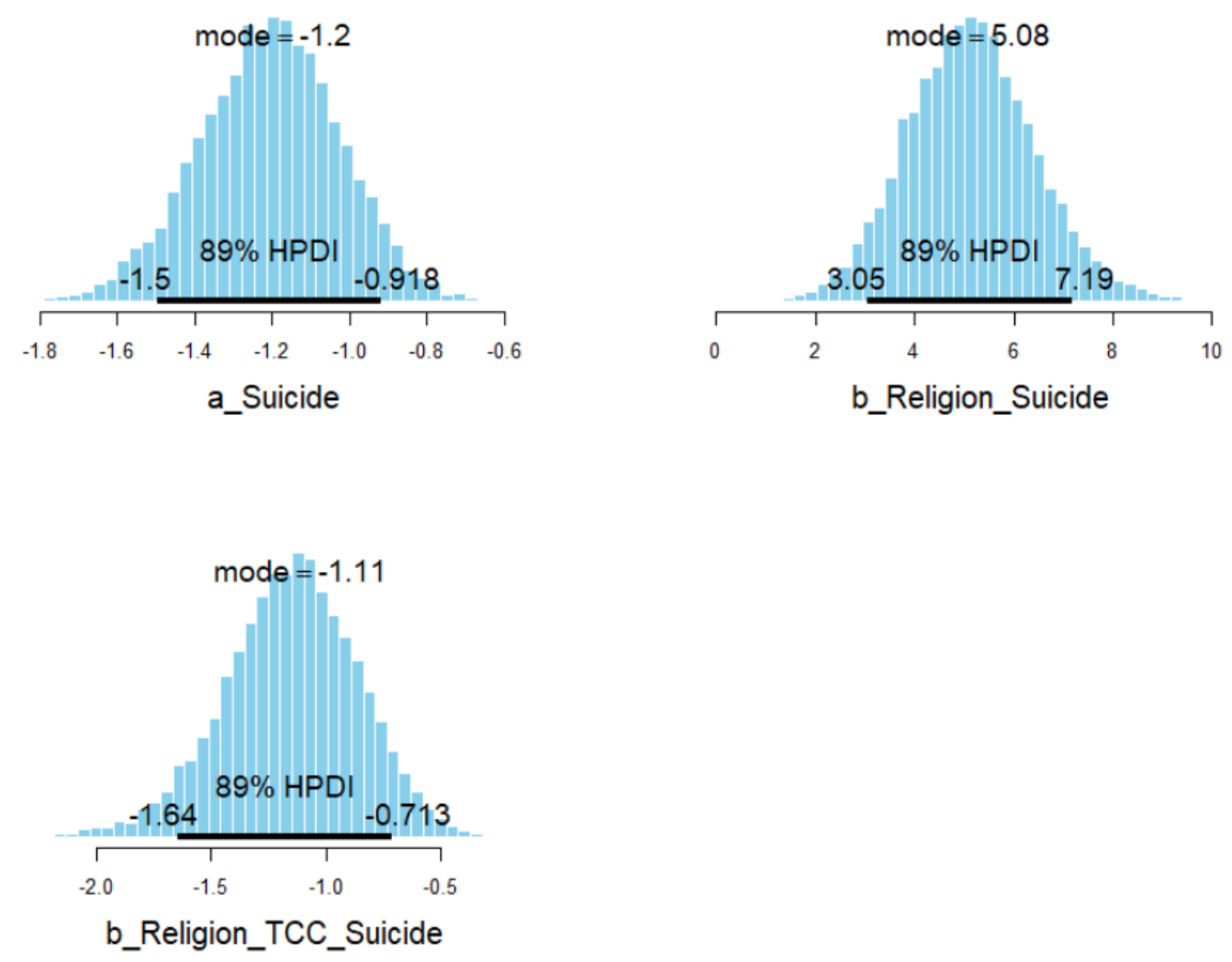

Figure 6: Distributions of Model 1b's posterior coefficients with HPDI at 89\%

\section{3. $\quad$ Model 2}

Table 4: Model 2's simulated posteriors.

\begin{tabular}{|c|c|c|c|c|}
\hline & Mean & SD & n_eff & Rhat \\
\hline Constant & 1.70 & 0.10 & 5707 & 1 \\
\hline Religion & 0.64 & 0.18 & 5404 & 1 \\
\hline
\end{tabular}

Diagnostic statistics hint that the coefficient's Markov chains are convergent (n_eff $>1,000$ and Rhat $=1$ ), and the model fits well with the data (see Figure 7). Model 2 shows that being religious is associated with a higher likelihood of seeking help from religious leaders (see Table 4 and Figures 8 and 9). 


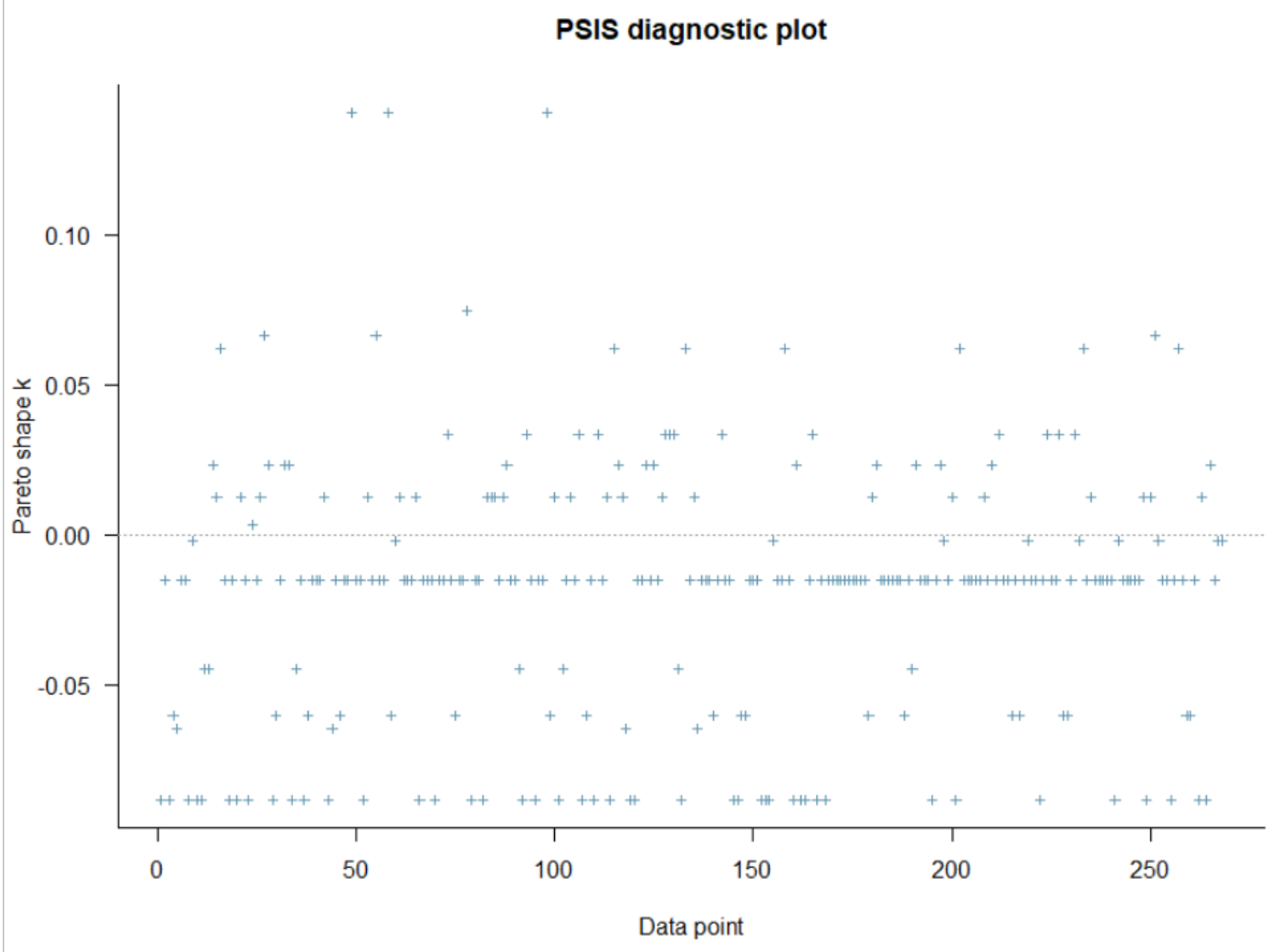

Figure 7: Model 2's PSIS diagnostic plot. 


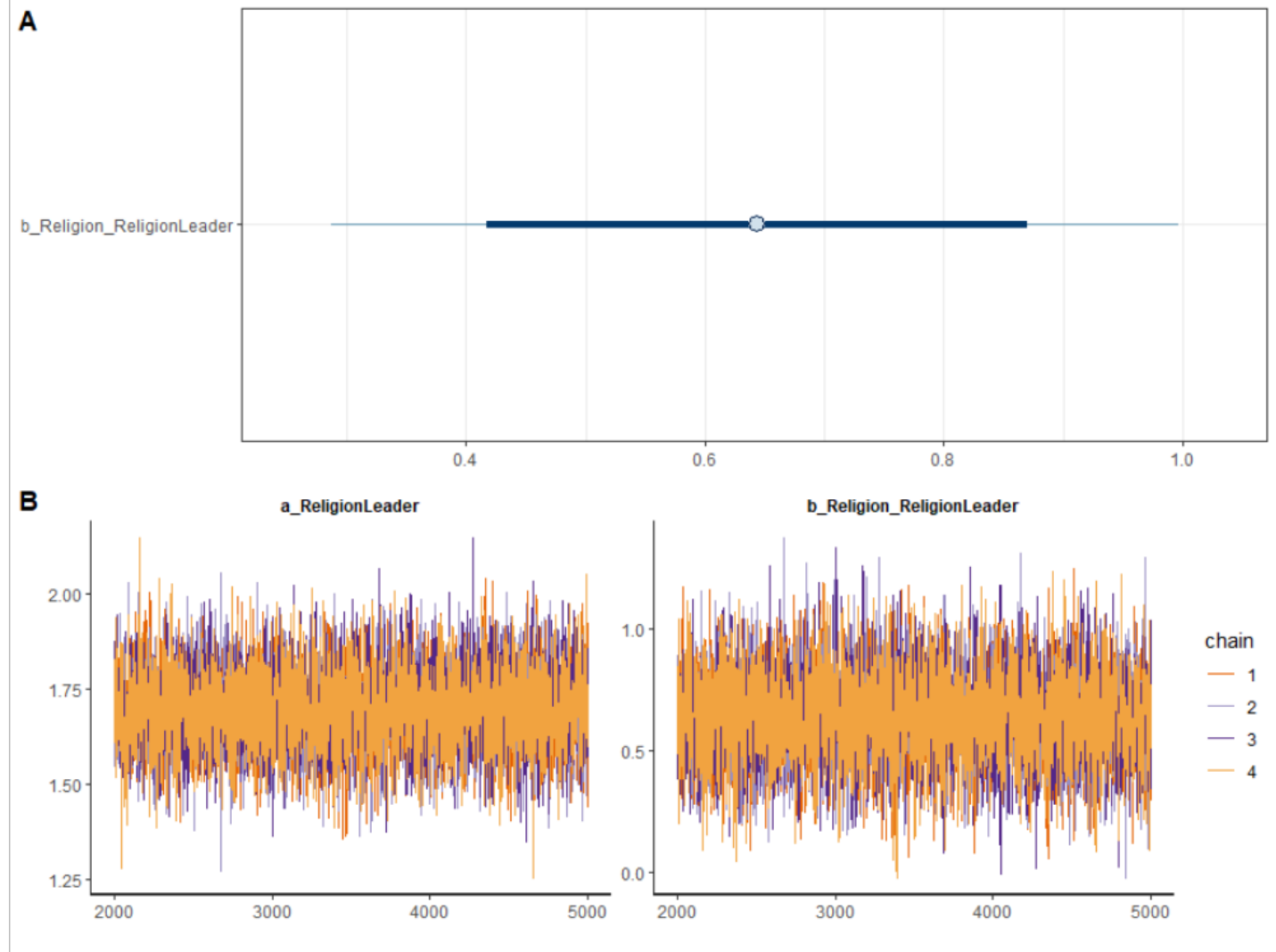

Figure 8: A - Interval plot for Model 2. B - Trace plots for Model 2 

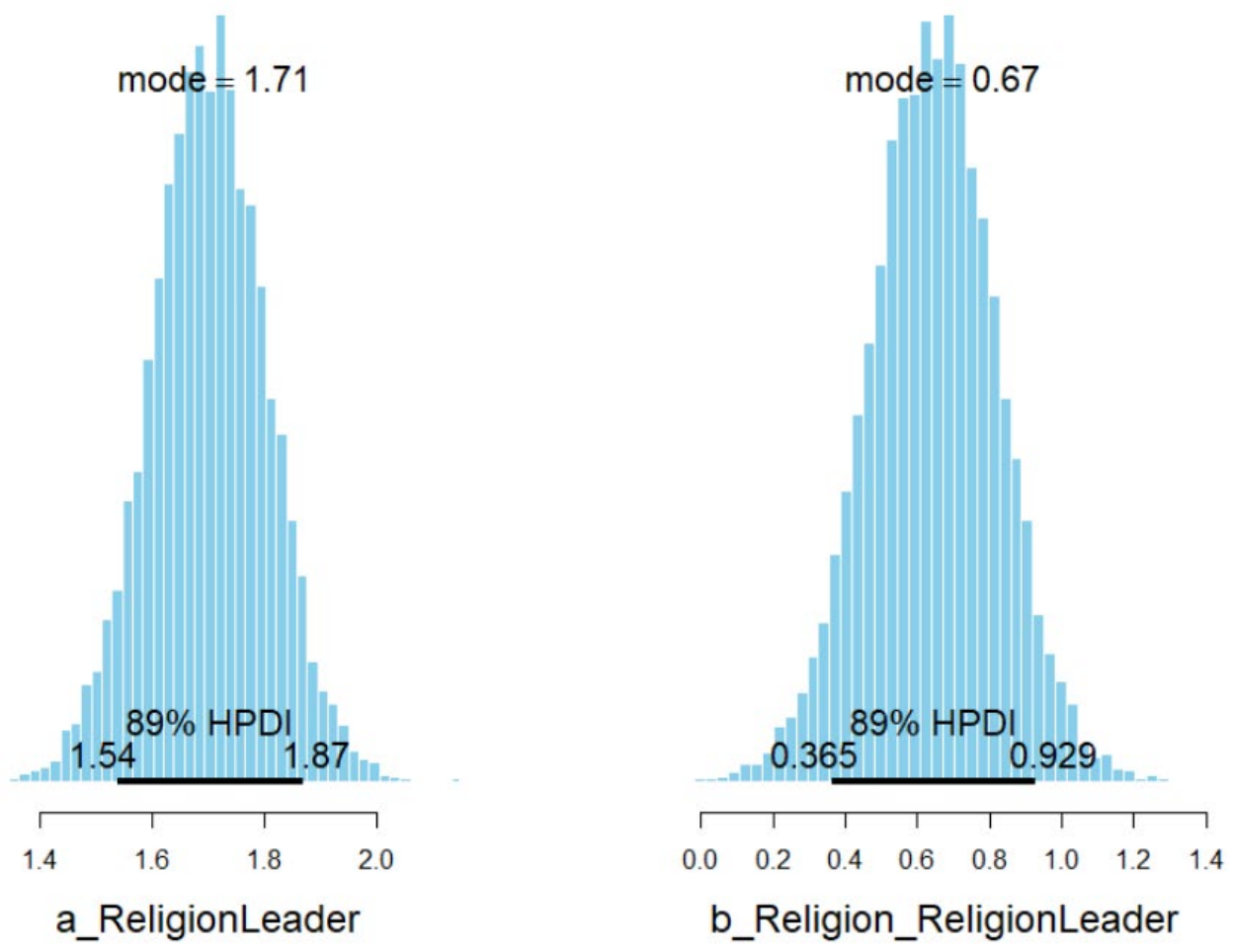

Figure 9: Distributions of Model 2's posterior coefficients with HPDI at 89\%

\subsection{Model $3 a$}

Table 5: Model 3a's simulated posteriors.

\begin{tabular}{|c|c|c|c|c|}
\hline & Mean & SD & n_eff & Rhat \\
\hline Constant & -1.30 & 0.24 & 3101 & 1 \\
\hline ReligionLeader & 0.04 & 0.10 & 3201 & 1 \\
\hline
\end{tabular}

Model 3a's result indicates no clear association between a likelihood to seek help from religious leaders and suicidal ideation (see Table 5 and Figure 10), so we continue performing the next model. 

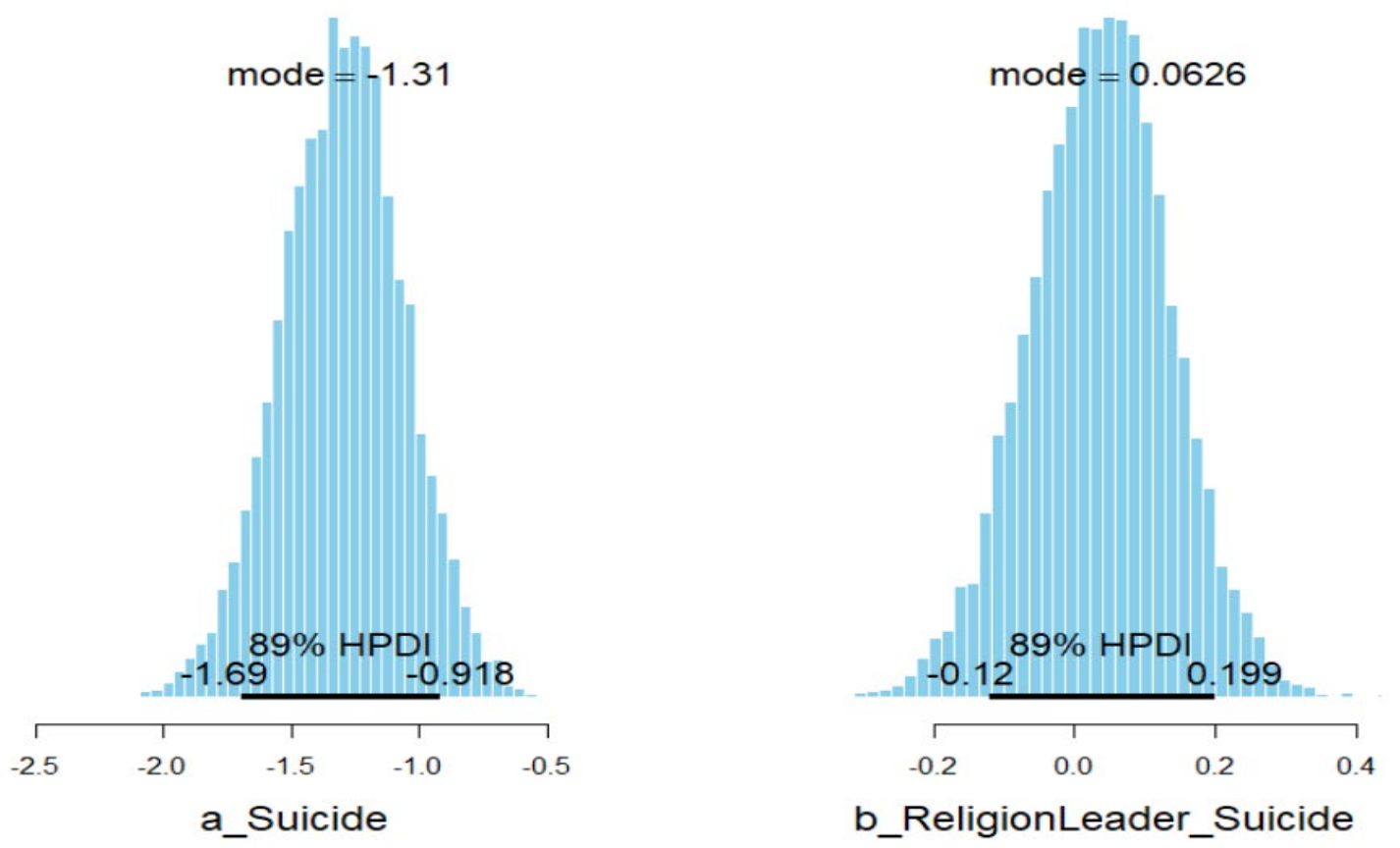

Figure 10: Distributions of Model 3a's posterior coefficients with HPDI at 89\%

\subsection{Model $3 b$}

Table 6: Model 3b's simulated posteriors.

\begin{tabular}{|c|c|c|c|c|}
\hline & Mean & SD & n_eff & Rhat \\
\hline Constant & -1.33 & 0.28 & 5391 & 1 \\
\hline ReligionLeader & 1.68 & 0.33 & 3731 & 1 \\
\hline ReligionLeader*TCC & -0.37 & 0.07 & 4014 & 1 \\
\hline
\end{tabular}

Model 3b's diagnostic statistics indicate a good convergence of Markov chains (n_eff $>1,000$ and Rhat $=1$ ) and the model's high goodness-of-fit with the data (see Table 6 and Figures 11, 12-B). Model $3 \mathrm{~b}$ shows that within students who are willing to seek help from religious leaders, those with a higher sense of connectedness tend to have lower suicidal ideation compared to those with a lower sense of connectedness (see Figures 12A). Figure 13 shows that the associations are highly reliable. 


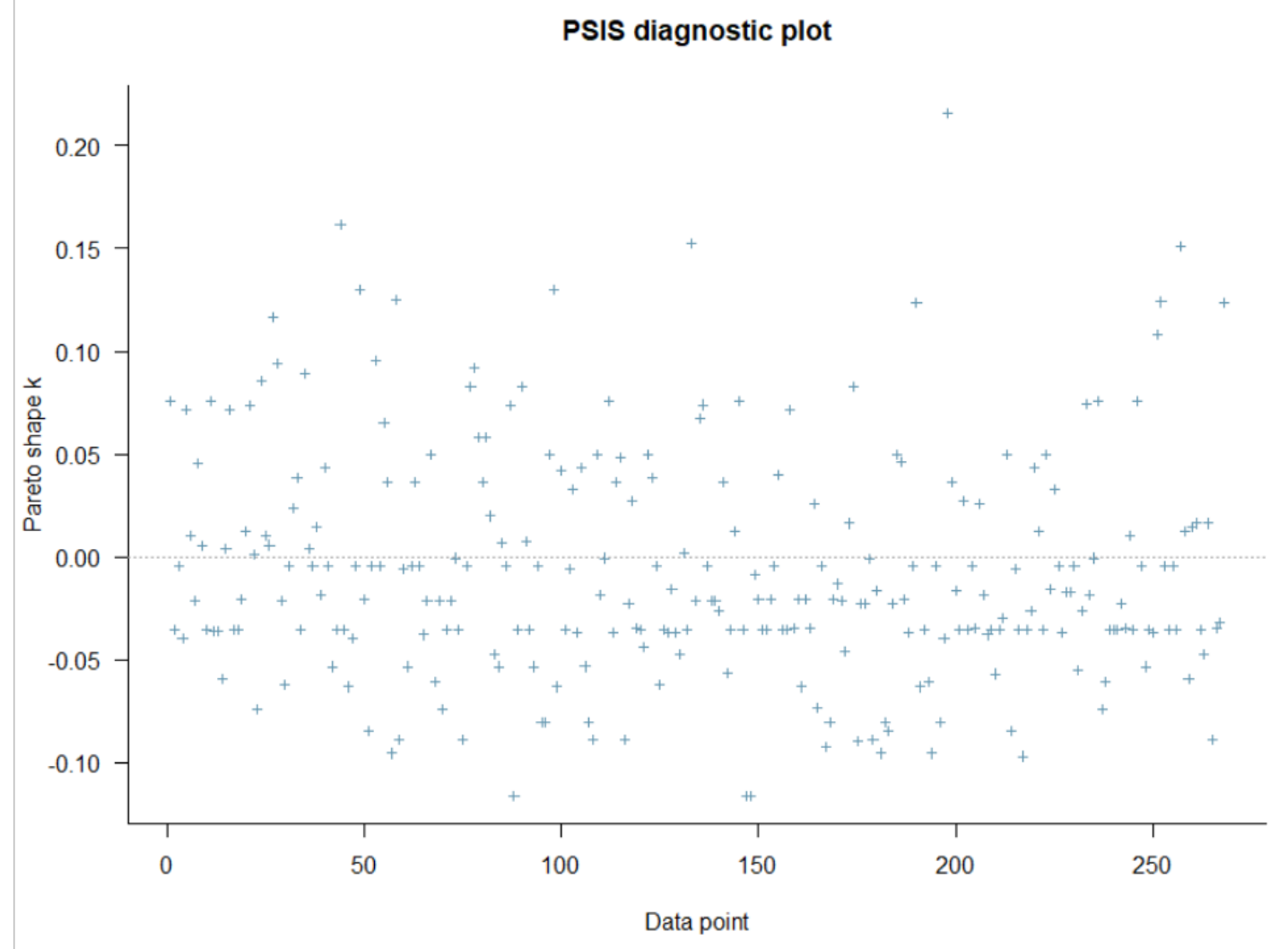

Figure 11: Model 3b's PSIS diagnostic plot. 


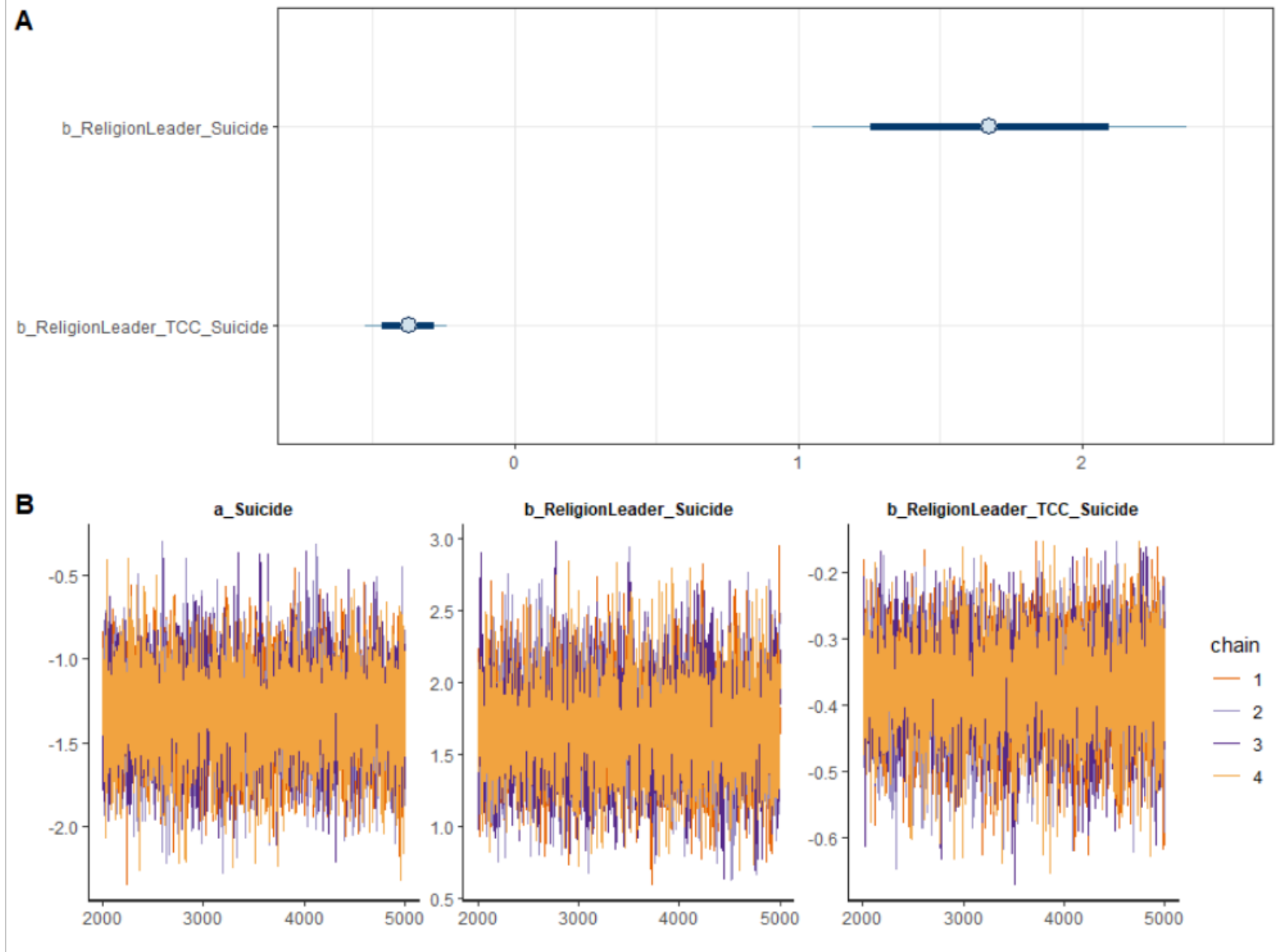

Figure 12: A - Interval plot for Model 3b. B - Trace plots for Model 3b 


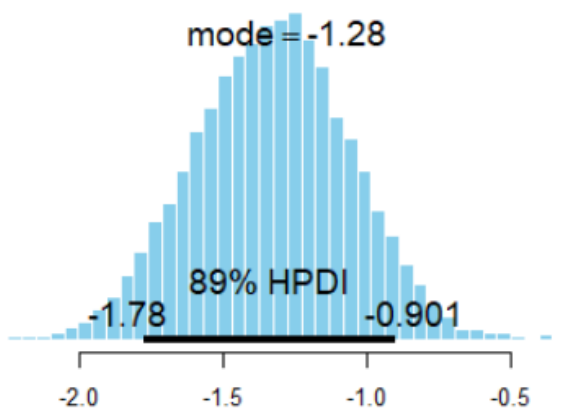

a_Suicide

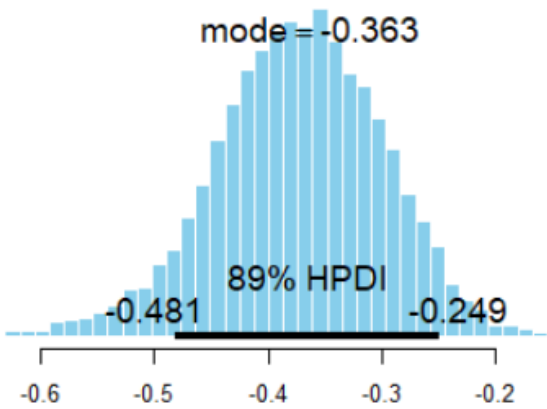

b_ReligionLeader_TCC_Suicide

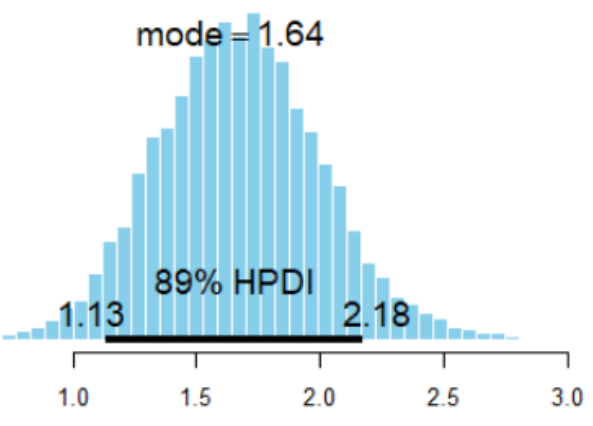

b_ReligionLeader_Suicide

Figure 13: Distributions of Model 3b's posterior coefficients with HPDI at 89\%

\section{Final remarks:}

The results and preliminary discussions above will be developed into a full-blown version of a research study in the future manuscript versions.

\section{References}

Darden, J. T. (2019). Tackling Terrorists' Exploitation of Youth: American Enterprise Institute. Hassan, R. (2014). Life as a weapon: The global rise of suicide bombings: Routledge.

Horowitz, M. C. (2015). The Rise and Spread of Suicide Bombing. Annual Review of Political Science, 18(1), 69-84. doi:10.1146/annurev-polisci-062813-051049

Kroenke, K., \& Spitzer, R. L. (2002). The PHQ-9: a new depression diagnostic and severity measure. Psychiatric Annals, 32(9), 509-515.

Kroenke, K., Spitzer, R. L., \& Williams, J. B. (2001). The PHQ-9: validity of a brief depression severity measure. Journal of General Internal Medicine, 16(9), 606-613. 
La, V.-P., \& Vuong, Q.-H. (2019). bayesvl: Visually learning the graphical structure of Bayesian networks and performing MCMC with'Stan'. The Comprehensive R Archive Network (CRAN).

Lee, R. M., \& Robbins, S. B. (1995). Measuring belongingness: The social connectedness and the social assurance scales. Journal of Counseling Psychology, 42(2), 232.

Nguyen, M.-H., Le, T.-T., Nguyen, H.-K. T., Ho, M.-T., Nguyen, H. T. T., \& Vuong, Q.-H. (2021). Alice in Suicideland: Exploring the Suicidal Ideation Mechanism through the Sense of Connectedness and Help-Seeking Behaviors. International Journal of Environmental Research and Public Health, 18(7). doi:10.3390/ijerph18073681

Pape, R. A. (2003). The Strategic Logic of Suicide Terrorism. The American Political Science Review, 97(3), 343-361.

Schweitzer, Y., Mendelboim, A., \& Hendler-Bloom, A. (2021). Suicide Bombings Worldwide in 2020. INSS Insight, 1424.

Shibley, T. (2002). Why Suicide Terrorism Takes Root. Brookings. https://www.brookings.edu/opinions/why-suicide-terrorism-takes-root/s

Vuong, Q.-H. (2016). Global Mindset as the Integration of Emerging Socio-Cultural Values Through Mindsponge Processes.

Vuong, Q.-H., \& La, V.-P. (2019). bayesvl: Visually Learning the Graphical Structure of Bayesian Networks and Performing MCMC with'Stan'.

Vuong, Q. H., \& Napier, N. K. (2015). Acculturation and global mindsponge: an emerging market perspective. International Journal of Intercultural Relations, 49, 354-367. 